doi:10.22306/al.v6i4.143

Received: 26 Nov. 2019

Accepted: 23 Dec. 2019

\title{
FORECASTING DEMAND IMPROVEMENT FOR REPLENISHMENT IN A RETAIL PAINTING COMPANY
}

\author{
Hugo Briseño-Oliveros \\ Universidad Popular Autónoma del Estado de Puebla A.C., 17 Sur 901, Barrio de Santiago, 72410, Puebla, Mexico, \\ hugo.briseno@upaep.edu.mx \\ Luis Antonio Guzmán-García \\ Universidad Popular Autónoma del Estado de Puebla A.C., 17 Sur 901, Barrio de Santiago, 72410, Puebla, Mexico, \\ luisantonio.guzman@upaep.edu.mx \\ Patricia Cano-Olivos \\ Universidad Popular Autónoma del Estado de Puebla A.C., 17 Sur 901, Barrio de Santiago, 72410, Puebla, Mexico, \\ patricia.cano@upaep.mx \\ Diana Sánchez-Partida
}

Universidad Popular Autónoma del Estado de Puebla A.C., 17 Sur 901, Barrio de Santiago, 72410, Puebla, Mexico, diana.sanchez@upaep.mx (corresponding author)

Keywords: forecast, MAPE, service level, economic order quantity, inventory management

Abstract: This case study was developed in a retail painting company; the main objective is to reach a higher cash flow for assuring the fulfilment of the demand with a $95 \%$ service level. Currently, supply chain faces to multiples competitors so familiar business have to improve the logistics processes for remaining in local, national and international markets. Through the ABC-classification, the product portfolio was classified for choosing the products with more significative impact. Forecasts techniques may obtain data with higher accuracy in the order preparation. For this research, a seasonal model is functional, since the demand tends to have a similar behaviour year by year and month by month. Seasonal demand model was used to find specific products that might not fit for ordering minimum quantities which might exceed the forecasted demand. On the other hand, classic EOQ model considers the value of the inventory and demand forecast, which demonstrates that the performance of the supply chain could improve considerably. Therefore, an accurate estimate can reduce inventory costs in each of the periods, satisfying customer demand, by at least $14 \%$. EOQ model should apply to all products for reducing the investment in slow-moving stock and improving the inventory for those highly demanded products which can generate flexibility to embrace market complexity and meet customer expectations. As a future study, the company can develop a strategy to reduce non-rotating inventory with more accurately, what and when they will sell specific products.

\section{Introduction}

This case study was developed a retail store of paintings because of; currently; consumers prefer buying from retailers because their trust is a sensible expectation [1]. Hence family firms are supposed to be more trustworthy compared to their nonfamily counterparts [2-4]. Therefore, family firms may obtain a strategic advantage based on policies and practices that cause them to appear to be more long-term oriented, credible, and reliable [5]. Capitalisation plays an essential role in the success of family firms [6-8]. Consequently, supply chain managers have to adapt their strategies to minimise inventories and maximise sales for facing their competitors [9]. It is crucial that calculates demand forecasts for decision-making that satisfy customer needs without having an excessive inventory to have a higher cash flow. For it, the company's portfolio products should segment through the ABC methodology, which acknowledges, which products are the most representative in terms of value-use.

ABC classification can help industrial marketers in three ways: costs estimate of products with significant differences specifications, proposing which product specifications may adjust in negotiations, and indicating the change company operations to reduce the cost that will allow satisfying customer [10]. Therefore, accurate and robust classification of items is required to manage a large number of products. ABC analysis, which is based on Pareto's principle, requires a single criterion, annual usage value (cost). Few items, which contribute a considerable amount of yearly usage value, are considered as A-class items and which provide very less amount of annual usage value, are considered as $\mathrm{C}$ class and $\mathrm{B}$ class. However, most of the companies store thousands of products and often they are not correctly categorised.

Additionally, $\mathrm{ABC}$ classification does not consider lead-time, inventory cost, commonality, obsolescence, substitutability, number of requests for an item per year, number of purchase orders per year, purchase order size of an item, scarcity, durability, repairability, stock ability, demand distribution and stock-out penalty cost, among others things [11]. To achieve supply chain competitiveness, having accurate data is a crucial factor 
[12]. However, supply chain managers cannot guarantee the accuracy of the forecasts [9] because the demand uncertainty and fickle consumers which unwilling to wait for replenishment if a product is momentarily unavailable $[13,14]$. Therefore, many supply chain managers rely on large inventory holdings as buffers to reduce the risk of product unavailability [15], which is not only costly but also generates inefficiencies throughout the supply chain.

Based on the case study company policies, materials should be ordered weekly. Therefore, supply chain management (SCM) supports to manage inter-company material, information, and financial flows to collectively enhance productivity, performance, and profitability $[16,17]$. Low costs across the supply chain, in addition to appropriate customer service levels, is seen as a crucial success factor [18]. Inventory management plays a vital role in obtaining a competitive advantage. Hence the main objective of inventory management practices is to have the requirements at the right time, in the right place with minimum cost. This proposal methodology reduces inventories, predict the demand for all $\mathrm{A}, \mathrm{B}$, and $\mathrm{C}$ classification SKUs, for each of the months and in turn have money available to invest on those materials with higher rotation or other special needs that arise.

\section{Background}

The proper management of assets held within an organization can be studied through inventory management models that is the reason for research and indepth analysis, as they constitute an essential item on the financial statements of any company. Optimizing the operation and management of these assets to achieve the fulfilment of its function without incurring excessive expenses is the objective of using these models and management tools.

The three key questions inventory management attempts to answer are i) How often should the inventory be reviewed? ii) When should an order be placed? iii) What size should the order be? [19].

The most common objectives when applying a management model are [20]:

- Minimize costs incurred by inventory management;

- Maximization of economic benefits, speaking of savings;

- Maximization of internal rate of return on inventory investment;

- Determine a feasible solution for better inventory management;

- Ensure flexibility in handling;

Faced with variations in demand and delays, organizations decide to work with safety stocks; this allows them to maintain the level of service that is vital to their operation [21].

Chikan [22] talks about a paradigm shift in business on different topics, as shown in the below table (Table 1).
Table 1 New paradigms in inventory management

\begin{tabular}{|c|c|}
\hline FIELD & PARADIGM \\
\hline $\begin{array}{l}\text { Economy of } \\
\text { services }\end{array}$ & $\begin{array}{l}\text { The requirements of today's } \\
\text { customers are not merely to } \\
\text { buy products, but to obtain } \\
\text { solutions to their problems. } \\
\text { Companies must offer the exact } \\
\text { combination of products and } \\
\text { services. }\end{array}$ \\
\hline E-Economy & $\begin{array}{l}\text { ICTs can achieve a level of } \\
\text { integration in the activities, } \\
\text { increasing availability, speed of } \\
\text { action, and reaction. }\end{array}$ \\
\hline $\begin{array}{l}\text { Network } \\
\text { economies }\end{array}$ & $\begin{array}{l}\text { Competition is now between } \\
\text { networks, so cooperation and } \\
\text { competition are now } \\
\text { interrelated. Achieving long- } \\
\text { term relationships and } \\
\text { strategic alliances. }\end{array}$ \\
\hline $\begin{array}{l}\text { An economy based } \\
\text { on knowledge }\end{array}$ & $\begin{array}{l}\text { Achieve competitive advantage } \\
\text { through experience. } \\
\text { Companies need more and } \\
\text { better information based on } \\
\text { more sophisticated decision } \\
\text { processes. }\end{array}$ \\
\hline $\begin{array}{l}\text { Responsible } \\
\text { economy }\end{array}$ & $\begin{array}{l}\text { The actors within the economy } \\
\text { are obliged to consider not only } \\
\text { their interests but with all their } \\
\text { surroundings. }\end{array}$ \\
\hline Global economy & $\begin{array}{l}\text { Decision-makers should } \\
\text { consider the global economy } \\
\text { when investing, buying, or } \\
\text { selling, as competitors, } \\
\text { customers, and partners can } \\
\text { come from anywhere. }\end{array}$ \\
\hline
\end{tabular}

The new paradigm is that inventories should now be an integral part of the value chain and in close relationship with other functions of the organization, thus becoming a strategic tool that achieves economic benefit and customer satisfaction, and their performance measures should be based on their contribution to finding better solutions for the consumer than those offered by competitors [22,20]. Customers expect immediate gratification from suppliers regarding their requirements, just as they have them with their customers or suppliers, but as Walker [23] states, they do not consider a different sourcing pattern. Therefore, it is necessary to make a sourcing plan that ensures the satisfaction of the requirements of retail customers. Regarding the analysis of demand, according to Howleg [24], the first step is to understand that there will be a difference between the real demand for materials and what is called artificial demand generated from organizational decisions. It is taken from the information that is available from customers, as well as the needs of the company itself, to know the demand from a forecast based on the behaviour of customer demand. 
Walker [23] believes that perfect compliance is one in which the right product can be delivered at the right price, time and quantity, meeting the stipulated quality standards. So, it is essential to start focusing on making consistent, reliable deliveries that achieve perfect compliance. Howleg [24] states that because customer demands are unstable and highly variable, companies are required to have a safety stock. Dwivedi and Butcher [25] point out that proper management of information is of paramount importance, as it can be used to optimize supply chain relationships, avoiding internal and external problems. Eagle [26], mentions that while forecasting, it should be considered accuracy of approximately $80 \%$, with variability that can have up to $40 \%$ additional, which as a result, will generate unbalanced inventories and prone to customer service gaps. Selecting from a variety of forecasting methods, the one with the highest accuracy plays a crucial role in the satisfaction of the company's customers.

\subsection{ABC classification and EOQ model}

For the present demand analysis, the $\mathrm{ABC}$ inventory classification technique is used, which is defined as an inventory control method based on the principle discovered by Pareto, who observed that $20 \%$ of the Italian population owned $80 \%$ of the land used, and later found that this principle could be applied to the economy [27]. The ABC methodology divides the company's sales into A for those SKUs which represent $15-20 \%$ of the inventory and whose profit to the company's revenue is close to $80 \%$; the B classification is for those products that are in stock with 30$35 \%$ of the volume and represent $15 \%$ of the profits, and finally the C class is for $50 \%$ of the items in inventory that contribute to $5 \%$ of the sales [28].

The classic EOQ concept equation 1 is born from the minimum intersection of the costs of maintaining the inventory with ordering costs; in this way, it can be assumed that it is an optimal value of units to be requested at the minimum possible cost [29].

$$
Q^{*}=\sqrt{\frac{2(D)\left(C_{o}\right)}{C h}}
$$

Where:

$Q^{*}=$ economic order quantity,

$D=$ forecasted demand in the planning horizon,

$C o=$ ordering cost per unit in the planning horizon,

$C h=$ holding cost per unit in the planning horizon.

Given that the company studied is a retailer, the allowable costs will be proportional to the total income, which must be considered in its finances, thinking that if the cost is less than the permissible point, it is a profit, or it would otherwise represent a loss [30].

\section{Research methodology}

This research was developed in different phases (figure 1):

a) Problem statement which describes the actual situation and needs of improvement in the logistics process,

b) information was collected on 52 weeks of sales in the company's product portfolio within five branches,

c) $\mathrm{ABC}$ analysis to determine those products which represent approximately $80 \%$ of the SKUs,

d) Demand forecast of A classification items looking for a maximum error of $10 \%$,

e) Inventory management, all active products in the portfolio must be kept in inventory, playing a key factor being able to determine a stock level that balances the level of service with the costs of inventory and associated with maintaining it, without impacting the company's cash flow,

f) Results analysis for making-decision.

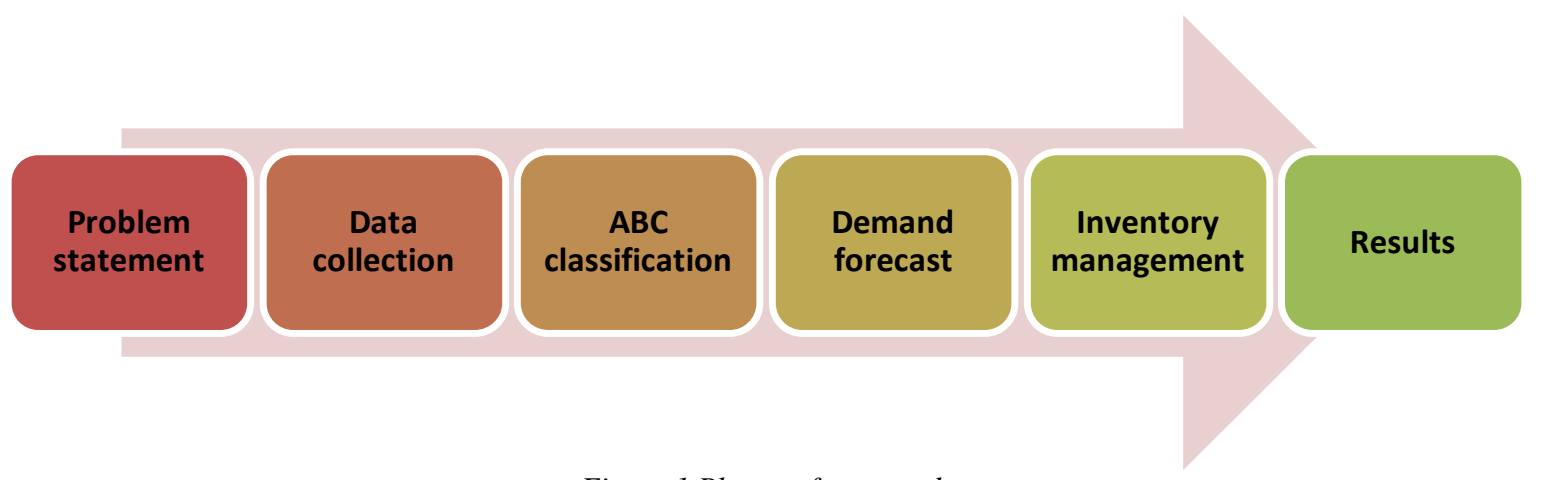

Figure 1 Phases of case study

\section{Case study \\ 4.1 Problem statement}

The case study was conducted in a family business of paintings which has many deficiencies due to lack of knowledge for decision-making of owners who are managers of the company. One of the main constraints faced is resistance to changes in strategies, due to the belief that current methods are functioning well, and it is not worth generate higher risk. Hence any improvement represents one of the biggest challenges so that the company has higher cash flow with lower inventory and maintaining the service level that has been handled since 
the beginning of the company. In the same way, there is the limitation of available working capital, since the reduced workforce and resources do not allow innovations to be made to the process for improvement projects to be developed. Furthermore, the company has excess inventory which generates high unnecessary holding costs that represent a constraint in terms of cash flow and space.

According with a company record, lost sales have reached $5 \%$ of yearly revenue due to shortages in high rotation items for the lack of financial capacity to pursue spot projects because of the elevated value of non-moving inventory. Another important implication is for certain B or $\mathrm{C}$ classification products its expiration dates exceed demand which causes additional fees for disposal of dangerous goods. Additionally, the inexistence of an accurate demand forecast and inventory planning strategy are impacting service level. Based on talks with the directors of the company, it is becoming more often that customers do not find the products approximately 5\% of the times which is the company's allowance maximum value to keep a strong relationship with their clients (service level target of 95\%). The purpose of this case study is applied ABC classification, forecasting techniques and EOQ model for increasing the cash flow monthly and service level.

\subsection{Data collection}

The data collection consisted of retrieving sales history from the company's ERP from the last twelve months. However, the data showed high variation, so that the sampling period was extended by thirty-six months. This sales history allowed to observe correlation and seasonality among similar periods over the years (Figure 2).

An A-class product was randomly selected to present a chart that describes the behaviour of the demand, it was observed that not all products have the same seasonality, however correlation between months over the years is pretty similar. From below chart, month 12 is the forecasted value as at the time of the development of the paper.

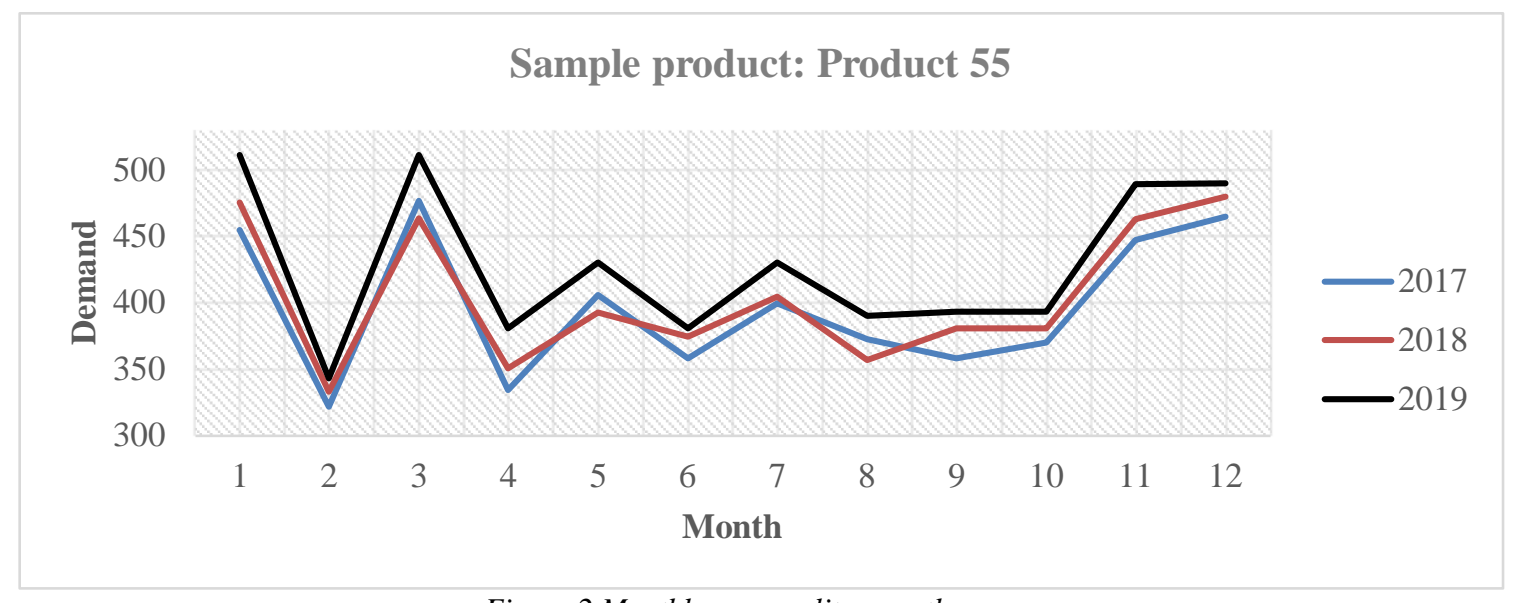

Figure 2 Monthly seasonality over the years

\subsection{ABC classification}

The total portfolio of the company consists of more than 1500 SKUs, which are necessary to keep in inventory and ensure service level. The higher value and rotation of a product, the more contribution on the sales it has and therefore it has a better ranking in the $\mathrm{ABC}$. It was found that only 56 SKUs fit A-class category, representing close to $75 \%$ of total sales, in contrast to the C-class products which represent more than $50 \%$ of the portfolio and only worth $5 \%$ of sales. Because of the significant impact on revenue of A-class products which are the main focus for applying techniques that improvement the processes logistics for increasing the levels service.

\subsection{Forecasting}

Once the analysis of the forecasts with traditional methods of time series (linear regression, simple exponential smoothing, Holt-Winters method, simple moving average, weighted and centred) was carried out, it was concluded that none of the models presented results that could approximate the demand of the products, having high errors than the objective established of $10 \%$ (Table 2). The centred moving average had the lowest average percentage error (MAPE 26\%), without reaching the desired value $(10 \%)$. However, this method consists of taking a group of observed values, calculating the average, and using it as a forecast for the following period only [32]. 


\begin{tabular}{|c|c|c|c|c|c|c|}
\hline \multirow{3}{*}{ PRODUCT } & $\begin{array}{c}\text { LINEAR } \\
\text { REGRESSION }\end{array}$ & $\begin{array}{c}\text { SIMPLE } \\
\text { MOVING } \\
\text { AVERAGE }\end{array}$ & $\begin{array}{c}\text { CENTRED } \\
\text { MOVING } \\
\text { AVERAGE }\end{array}$ & $\begin{array}{c}\text { WEIGHTED } \\
\text { MOVING } \\
\text { AVERAGE }\end{array}$ & $\begin{array}{c}\text { EXPONPLE } \\
\text { SMONENIAL }\end{array}$ & $\begin{array}{c}\text { HOLT- } \\
\text { WINTERS }\end{array}$ \\
\hline $\mathbf{1 , \ldots . . 5 6}$ & $\mathbf{3 6 \%}$ & $\mathbf{3 9 \%}$ & $\mathbf{2 6 \%}$ & $\mathbf{4 0 \%}$ & $\mathbf{3 9 \%}$ & $\mathbf{3 7 \%}$ \\
\hline
\end{tabular}

For a forecast to be considered adequate, it is essential to remember that the value of the MAPE must be no more than $10 \%$, the same value that was established as the objective for the analysis developed. Due to the 56 products of A classification show correlation and seasonality as well as external factors that intervene and motivate customers to buy certain products. For the demand of 52 weeks was applied a seasonal forecast that knowing the market trend in recent years will make it possible to adjust the amount of material that will be required in each of the months for the following periods.

Within a seasonal forecast, it is vital to consider three critical components which are: first the level, which allows separating the seasonality of the base values of the estimates. In the second place, seasonality, which will modify the values for the seasonal variations that are shown in the estimates and, finally, the tendency value that will allow adjusting the estimate to the variations or propensities through time [33].

Once the demand per month has been consolidated over the last three years, the average demand is calculated for each of the months during the period stipulated by equation 2. Subsequently, the seasonality index is obtained for each month (equation 3). Afterwards, estimate the annual demand for the year to be forecast as the product of equation 4 by equation 5 . And finally, obtain the product of equation 5 by equation 3 , with this, it is possible to know the forecast of seasonal sales.

$$
\begin{aligned}
& P_{i}=\frac{\sum_{j=1}^{m} D_{i}}{m} \\
& S_{\text {index }}=\frac{\frac{1}{n} \sum_{j=1}^{m} D_{i j}}{\frac{1}{n} \sum_{j=1}^{m} D_{i}} \\
& T_{i}=\frac{D_{j}}{D_{j-1}} \\
& D_{\text {monthly }}=\frac{D_{j}}{n}
\end{aligned}
$$

Where:

$P=$ Average demand in the sampled period,

$D=$ Demand in the planning horizon,
$S_{\text {index }}=$ Seasonality index for each of the periods in the planning horizon,

$T=$ Projected tendency year over year,

$i=1,2, \ldots, n$ (months),

$j=1,2, \ldots . ., m$ (years).

It is observed that in the months where there are demand peaks, the index is equation 3 is greater than value 1 during the months of lower sales concerning the forecast average, equation 3 will have a value less than 1, which is the factor between the seasonality compared with the average demand historical data for period $i$ for each of the items (Table 3).

MAPE for the A-class sample of 56 products yields a value of $9.18 \%$, so that meets the objective of $10 \%$ error in 53 of 56 articles studied, which will allow replicating the model to the category A products within the company's portfolio with an accuracy in demand forecast of at least $90 \%$ (Figure 3 ), this result is considered highly reliable [34]. Table 4 shows the demand forecast.

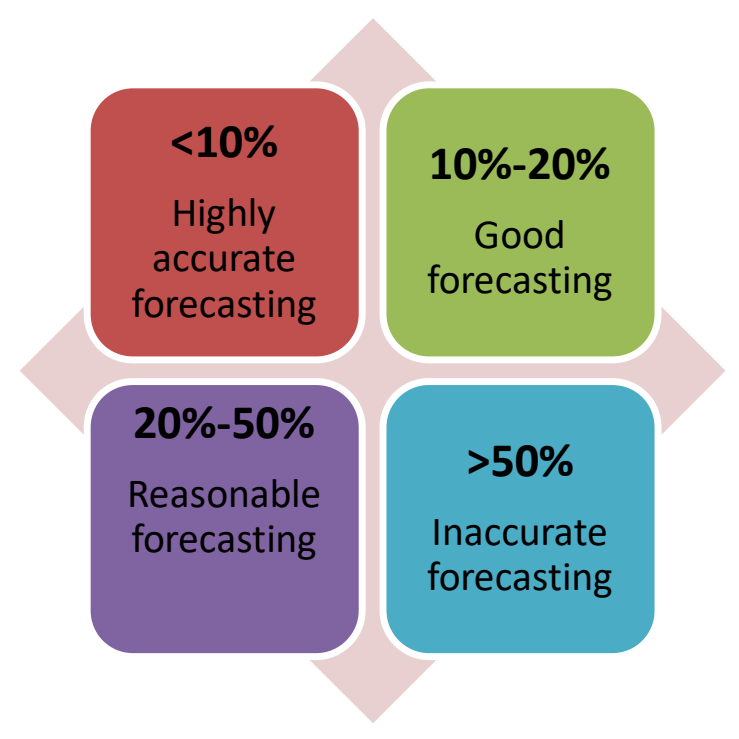

Figure 3 MAPE evaluation criteria 
FORECASTING DEMAND IMPROVEMENT FOR REPLENISHMENT IN A RETAIL PAINTING COMPANY

Hugo Briseño-Oliveros; Luis Antonio Guzmán-García; Patricia Cano-Olivos; Diana Sánchez-Partida

Table 3 MAPE results for seasonal forecasts of A class SKUs

\begin{tabular}{|c|c|c|c|c|c|c|c|c|c|c|c|}
\hline \multirow{2}{*}{ ITEM } & \multicolumn{10}{|c|}{ PERIOD } & \multirow{2}{*}{ MAPE } \\
\hline & 1 & 2 & 3 & 4 & 5 & 6 & 7 & 8 & 9 & 10 & \\
\hline PRODUCT 1 & 0.05 & 0.06 & \begin{tabular}{|l|}
0.03 \\
\end{tabular} & \begin{tabular}{|l|}
0.05 \\
\end{tabular} & 0.02 & \begin{tabular}{|l|}
0.08 \\
\end{tabular} & \begin{tabular}{|l|}
0.04 \\
\end{tabular} & \begin{tabular}{|l|}
0.08 \\
\end{tabular} & 0.05 & \begin{tabular}{|l|}
0.04 \\
\end{tabular} & $5.12 \%$ \\
\hline PRODUCT 2 & 0.04 & 0.04 & \begin{tabular}{|l|}
0.14 \\
\end{tabular} & \begin{tabular}{|l|}
0.15 \\
\end{tabular} & \begin{tabular}{|l|}
0.08 \\
\end{tabular} & \begin{tabular}{|l|}
0.04 \\
\end{tabular} & \begin{tabular}{|l|}
0.17 \\
\end{tabular} & 0.11 & \begin{tabular}{|l|}
0.00 \\
\end{tabular} & \begin{tabular}{|l|}
0.16 \\
\end{tabular} & $9.39 \%$ \\
\hline PRODUCT 3 & 0.04 & 0.04 & 0.04 & 0.13 & 0.04 & 0.21 & 0.20 & 0.06 & 0.06 & 0.04 & $8.72 \%$ \\
\hline PRODUCT 4 & 0.04 & 0.04 & 0.04 & \begin{tabular}{|l|}
0.12 \\
\end{tabular} & \begin{tabular}{|l|l|}
0.04 \\
\end{tabular} & \begin{tabular}{|l|l|}
0.06 \\
\end{tabular} & $\mathbf{0 . 1 0}$ & $\mathbf{0 . 0 3}$ & \begin{tabular}{|l|}
0.04 \\
\end{tabular} & 0.21 & $7.36 \%$ \\
\hline PRODUCT 5 & 0.13 & 0.11 & 0.09 & \begin{tabular}{|l|}
0.07 \\
\end{tabular} & $\mathbf{0 . 0 3}$ & 0.14 & 0.09 & 0.07 & \begin{tabular}{|l|}
0.04 \\
\end{tabular} & \begin{tabular}{|l|}
0.04 \\
\end{tabular} & $8.37 \%$ \\
\hline PRODUCT 6 & 0.04 & 0.06 & \begin{tabular}{|l|}
$\mathbf{0 . 0 7}$ \\
\end{tabular} & \begin{tabular}{|l|}
0.05 \\
\end{tabular} & $\mathbf{0 . 0 5}$ & \begin{tabular}{|l|}
0.04 \\
\end{tabular} & \begin{tabular}{|l|}
0.15 \\
\end{tabular} & 0.13 & \begin{tabular}{|l|}
0.13 \\
\end{tabular} & \begin{tabular}{|l|}
$\mathbf{0 . 0 7}$ \\
\end{tabular} & $7.87 \%$ \\
\hline PRODUCT 7 & 0.14 & 0.04 & 0.20 & \begin{tabular}{|l|}
0.01 \\
\end{tabular} & \begin{tabular}{|l|l|}
0.00 \\
\end{tabular} & \begin{tabular}{|l|}
0.04 \\
\end{tabular} & \begin{tabular}{|l|}
0.24 \\
\end{tabular} & \begin{tabular}{|l|}
0.09 \\
\end{tabular} & \begin{tabular}{|l|}
0.04 \\
\end{tabular} & \begin{tabular}{|l|}
0.15 \\
\end{tabular} & $9.69 \%$ \\
\hline PRODUCT 8 & 0.12 & 0.09 & 0.09 & 0.16 & \begin{tabular}{|l|l|}
0.04 \\
\end{tabular} & \begin{tabular}{|l|}
0.11 \\
\end{tabular} & \begin{tabular}{|l|}
0.06 \\
\end{tabular} & \begin{tabular}{|l|}
0.04 \\
\end{tabular} & \begin{tabular}{|l|}
0.04 \\
\end{tabular} & \begin{tabular}{|l|}
0.04 \\
\end{tabular} & $7.96 \%$ \\
\hline PRODUCT 9 & 0.07 & 0.39 & 0.33 & \begin{tabular}{|l|}
0.14 \\
\end{tabular} & \begin{tabular}{|l|l|}
0.04 \\
\end{tabular} & 0.24 & 0.04 & 0.11 & 0.90 & 0.14 & $24.20 \%$ \\
\hline PRODUCT 10 & 0.02 & 0.16 & 0.03 & \begin{tabular}{|l|}
0.08 \\
\end{tabular} & \begin{tabular}{|l|}
0.04 \\
\end{tabular} & \begin{tabular}{|l|}
0.23 \\
\end{tabular} & 0.07 & 0.15 & \begin{tabular}{ll|}
0.02 \\
\end{tabular} & $\mathbf{0 . 0 3}$ & $8.32 \%$ \\
\hline PRODUCT 11 & 0.16 & 0.04 & \begin{tabular}{|l|}
0.09 \\
\end{tabular} & \begin{tabular}{|l|}
0.15 \\
\end{tabular} & \begin{tabular}{|l|l|}
0.04 \\
\end{tabular} & \begin{tabular}{|l|}
0.04 \\
\end{tabular} & \begin{tabular}{|l|}
0.11 \\
\end{tabular} & 0.10 & \begin{tabular}{|l|}
0.01 \\
\end{tabular} & \begin{tabular}{|l|}
0.17 \\
\end{tabular} & $9.16 \%$ \\
\hline PRODUCT 12 & 0.10 & 0.17 & 0.04 & \begin{tabular}{|l|}
0.04 \\
\end{tabular} & 0.13 & $\mathbf{0 . 0 3}$ & \begin{tabular}{|l|}
0.02 \\
\end{tabular} & 0.18 & 0.04 & 0.04 & $8.12 \%$ \\
\hline PRODUCT 13 & 0.04 & 0.04 & 0.04 & 0.13 & \begin{tabular}{|l|l|}
0.04 \\
\end{tabular} & 0.10 & 0.04 & 0.04 & 0.06 & \begin{tabular}{|l|}
0.04 \\
\end{tabular} & $5.95 \%$ \\
\hline PRODUCT 14 & 0.09 & 0.00 & 0.06 & \begin{tabular}{|l|}
0.10 \\
\end{tabular} & 0.01 & 0.04 & $\mathbf{0 . 0 1}$ & 0.29 & 0.19 & \begin{tabular}{|l|}
0.09 \\
\end{tabular} & $8.71 \%$ \\
\hline PRODUCT 15 & 0.10 & 0.04 & 0.06 & \begin{tabular}{|l|}
0.13 \\
\end{tabular} & \begin{tabular}{|l|}
0.04 \\
\end{tabular} & \begin{tabular}{|l|}
0.04 \\
\end{tabular} & \begin{tabular}{|l|}
0.12 \\
\end{tabular} & 0.15 & \begin{tabular}{|l|}
0.01 \\
\end{tabular} & \begin{tabular}{|l|}
0.09 \\
\end{tabular} & $7.82 \%$ \\
\hline PRODUCT 16 & 0.12 & 0.10 & \begin{tabular}{|l|}
0.09 \\
\end{tabular} & \begin{tabular}{|l|}
0.17 \\
\end{tabular} & 0.04 & \begin{tabular}{|l|}
0.04 \\
\end{tabular} & \begin{tabular}{|l|}
0.06 \\
\end{tabular} & 0.12 & 0.04 & $\mathbf{0 . 0 7}$ & $8.49 \%$ \\
\hline PRODUCT 17 & 0.04 & 0.04 & 0.04 & \begin{tabular}{|l|}
0.36 \\
\end{tabular} & $\mathbf{0 . 1 0}$ & \begin{tabular}{|l|}
0.04 \\
\end{tabular} & \begin{tabular}{|l|}
0.04 \\
\end{tabular} & \begin{tabular}{|l|}
0.21 \\
\end{tabular} & 0.04 & \begin{tabular}{|l|}
0.04 \\
\end{tabular} & $9.70 \%$ \\
\hline PRODI & 0.10 & 0.10 & 0.13 & \begin{tabular}{|l|}
0.17 \\
\end{tabular} & $\mathbf{0 . 1 0}$ & 0.04 & 0.10 & \begin{tabular}{|l|}
0.04 \\
\end{tabular} & (0.03 & 0.10 & $23 \%$ \\
\hline PRODUCT 19 & 0.08 & 0.24 & 0.03 & \begin{tabular}{|l|}
0.14 \\
\end{tabular} & \begin{tabular}{|l|l|}
0.04 \\
\end{tabular} & \begin{tabular}{|l|}
0.08 \\
\end{tabular} & $\mathbf{0 . 0 3}$ & 0.04 & \begin{tabular}{|l|}
0.04 \\
\end{tabular} & 0.06 & $8.00 \%$ \\
\hline PRODUCT 20 & 0.24 & 0.13 & \begin{tabular}{|l|}
0.13 \\
\end{tabular} & \begin{tabular}{|l|}
0.04 \\
\end{tabular} & \begin{tabular}{|l|l|}
0.04 \\
\end{tabular} & 0.16 & 0.04 & 0.10 & \begin{tabular}{|l|}
0.04 \\
\end{tabular} & 0.06 & $9.99 \%$ \\
\hline PRODUCT 21 & 0.10 & 0.04 & 0.16 & \begin{tabular}{|l|l|}
0.17 \\
\end{tabular} & \begin{tabular}{|l|}
0.01 \\
\end{tabular} & \begin{tabular}{|l|}
0.13 \\
\end{tabular} & \begin{tabular}{|l|}
0.03 \\
\end{tabular} & \begin{tabular}{|l|}
0.10 \\
\end{tabular} & $\mathbf{0 . 1 0}$ & \begin{tabular}{|l|}
0.01 \\
\end{tabular} & $8.60 \%$ \\
\hline PRODUCT 22 & 0.11 & 0.04 & 0.04 & \begin{tabular}{|l|}
0.04 \\
\end{tabular} & 0.17 & 0.04 & \begin{tabular}{|l|}
0.04 \\
\end{tabular} & 0.33 & \begin{tabular}{|l|}
0.04 \\
\end{tabular} & 0.04 & $9.17 \%$ \\
\hline PRODI & 0.04 & 0.13 & 0.04 & \begin{tabular}{|l|}
0.04 \\
\end{tabular} & 0.21 & \begin{tabular}{|l|l|}
0.13 \\
\end{tabular} & 0.21 & 0.04 & \begin{tabular}{|l|}
0.04 \\
\end{tabular} & \begin{tabular}{|l|}
0.04 \\
\end{tabular} & $9.37 \%$ \\
\hline PRODUCT 24 & 0.16 & 0.09 & 0.07 & \begin{tabular}{|l|}
0.00 \\
\end{tabular} & \begin{tabular}{|l|l|}
0.08 \\
\end{tabular} & \begin{tabular}{|l|l|}
0.02 \\
\end{tabular} & $\mathbf{0 . 1 7}$ & 0.01 & 0.15 & \begin{tabular}{|l|}
0.04 \\
\end{tabular} & $8.04 \%$ \\
\hline PRODUCT 25 & $\mathbf{0 . 0 3}$ & 0.06 & 0.11 & 0.16 & 0.18 & 0.10 & 0.05 & 0.14 & 0.08 & $\mathbf{0 . 0 3}$ & $9.46 \%$ \\
\hline PRODUCT 26 & 0.15 & 0.13 & 0.13 & \begin{tabular}{|l|}
0.08 \\
\end{tabular} & 0.02 & \begin{tabular}{|l|}
0.0 \\
\end{tabular} & \begin{tabular}{|l|}
0.06 \\
\end{tabular} & \begin{tabular}{|l|}
0.02 \\
\end{tabular} & \begin{tabular}{ll|}
0.01 \\
\end{tabular} & \begin{tabular}{|l|}
0.06 \\
\end{tabular} & $7.11 \%$ \\
\hline PRODUCT 27 & 0.10 & 0.16 & 0.08 & \begin{tabular}{|l|}
0.02 \\
\end{tabular} & 0.11 & 0.11 & \begin{tabular}{|l|}
0.19 \\
\end{tabular} & 0.06 & 0.05 & 0.04 & $9.16 \%$ \\
\hline PRODUCT 28 & 0.04 & 0.13 & 0.08 & \begin{tabular}{|l|}
0.08 \\
\end{tabular} & \begin{tabular}{|l|l|}
0.17 \\
\end{tabular} & 0.13 & 0.01 & 0.16 & \begin{tabular}{|l|}
0.04 \\
\end{tabular} & 0.06 & $9.15 \%$ \\
\hline CT 29 & 0.04 & 0.00 & 0.04 & |0.08 & 0.09 & 0.43 & \begin{tabular}{|l|}
0.05 \\
\end{tabular} & 0.08 & $\mathbf{0 . 0 3}$ & 0.06 & $9.05 \%$ \\
\hline PRODUCT 30 & 0.20 & 0.01 & 0.07 & 0.08 & \begin{tabular}{|l|l|}
0.06 \\
\end{tabular} & 0.05 & 0.05 & 0.12 & 0.11 & \begin{tabular}{|l|}
0.09 \\
\end{tabular} & $8.49 \%$ \\
\hline PRODUCT 31 & 0.16 & 0.09 & 0.08 & \begin{tabular}{|l|}
0.04 \\
\end{tabular} & $\mathbf{0 . 0 2}$ & 0.12 & 0.10 & 0.17 & 0.07 & 0.14 & $9.96 \%$ \\
\hline PRODUCT 32 & 0.16 & 0.15 & 0.10 & \begin{tabular}{|l|}
0.10 \\
\end{tabular} & \begin{tabular}{|l|l|}
0.21 \\
\end{tabular} & 0.00 & $\mathbf{0 . 0 2}$ & 0.16 & \begin{tabular}{|l|}
0.02 \\
\end{tabular} & \begin{tabular}{|l|}
0.08 \\
\end{tabular} & $9.96 \%$ \\
\hline PRODUCT 33 & 0.12 & $\mathbf{0 . 0 3}$ & 0.00 & \begin{tabular}{|l|}
0.02 \\
\end{tabular} & 0.06 & 0.04 & \begin{tabular}{|l|}
0.00 \\
\end{tabular} & 0.04 & 0.06 & 0.53 & $9.05 \%$ \\
\hline PRODUCT 34 & 0.13 & 0.15 & 0.10 & \begin{tabular}{|l|}
0.10 \\
\end{tabular} & \begin{tabular}{|l|l|}
0.04 \\
\end{tabular} & 0.01 & \begin{tabular}{|l|}
0.06 \\
\end{tabular} & 0.11 & $\mathbf{0 . 0 1}$ & \begin{tabular}{|l|}
0.01 \\
\end{tabular} & $7.38 \%$ \\
\hline PRODUCT 35 & 0.02 & 0.06 & 0.13 & \begin{tabular}{|l|}
0.02 \\
\end{tabular} & \begin{tabular}{|l|}
0.08 \\
\end{tabular} & \begin{tabular}{|l|l|}
0.15 \\
\end{tabular} & 0.11 & 0.13 & \begin{tabular}{|l|}
0.19 \\
\end{tabular} & \begin{tabular}{|l|}
0.04 \\
\end{tabular} & $9.40 \%$ \\
\hline PRODUCT 36 & 0.17 & 0.05 & 0.05 & \begin{tabular}{|l|}
0.01 \\
\end{tabular} & \begin{tabular}{|l|}
0.09 \\
\end{tabular} & 0.03 & 0.14 & 0.14 & 0.15 & 0.11 & $9.45 \%$ \\
\hline PRODUCT 37 & 0.02 & 0.04 & 0.11 & \begin{tabular}{|l|}
0.10 \\
\end{tabular} & \begin{tabular}{|l|}
0.19 \\
\end{tabular} & 0.02 & 0.03 & 0.21 & \begin{tabular}{|l|l|}
0.07 \\
\end{tabular} & \begin{tabular}{|l|}
0.04 \\
\end{tabular} & $8.41 \%$ \\
\hline PRODUCT 38 & 0.17 & 0.04 & 0.06 & 0.06 & \begin{tabular}{|l|l|}
0.02 \\
\end{tabular} & 0.10 & 0.12 & 0.14 & 0.21 & \begin{tabular}{|l|}
0.02 \\
\end{tabular} & $9.47 \%$ \\
\hline PRODUCT 39 & 0.07 & 0.10 & 0.12 & \begin{tabular}{|l|}
0.11 \\
\end{tabular} & 0.13 & 0.10 & \begin{tabular}{|l|}
0.03 \\
\end{tabular} & 0.01 & 0.12 & \begin{tabular}{|l|}
0.04 \\
\end{tabular} & $8.35 \%$ \\
\hline PRODUCT 40 & 0.11 & 0.01 & 0.17 & \begin{tabular}{|l|}
0.04 \\
\end{tabular} & $\mathbf{0 . 1 0}$ & 0.11 & 0.15 & 0.09 & 0.10 & \begin{tabular}{|l|}
0.04 \\
\end{tabular} & $9.26 \%$ \\
\hline PRODUCT 41 & 0.03 & 0.05 & 0.13 & (0.03 & \begin{tabular}{|l|l|}
$\mathbf{0 . 0 7}$ \\
\end{tabular} & 0.09 & $\mathbf{0 . 0 7}$ & 0.12 & 0.14 & $\mathbf{0 . 1 0}$ & $8.31 \%$ \\
\hline PRODUCT 42 & 0.13 & 0.01 & 0.14 & \begin{tabular}{|l|}
0.09 \\
\end{tabular} & 0.00 & 0.18 & $\mathbf{0 . 0 3}$ & 0.05 & 0.01 & $\mathbf{0 . 0 0}$ & $6.40 \%$ \\
\hline PRODUCT 43 & 0.20 & 0.01 & \begin{tabular}{|l|}
0.09 \\
\end{tabular} & \begin{tabular}{|l|}
0.23 \\
\end{tabular} & \begin{tabular}{|l|l|}
0.11 \\
\end{tabular} & \begin{tabular}{|l|}
0.05 \\
\end{tabular} & 0.14 & 0.01 & 0.10 & \begin{tabular}{|l|}
0.09 \\
\end{tabular} & $10.25 \%$ \\
\hline PRODUCT 44 & 0.04 & 0.10 & 0.14 & \begin{tabular}{|l|}
0.04 \\
\end{tabular} & 0.11 & 0.06 & 0.07 & 0.14 & 0.09 & 0.12 & $9.17 \%$ \\
\hline PRODUCT 45 & 0.01 & 0.09 & 0.07 & \begin{tabular}{|c|}
0.26 \\
\end{tabular} & \begin{tabular}{|l|}
0.27 \\
\end{tabular} & \begin{tabular}{|l|}
0.08 \\
\end{tabular} & 0.06 & 0.04 & \begin{tabular}{|l|}
0.02 \\
\end{tabular} & \begin{tabular}{|l|}
0.05 \\
\end{tabular} & $9.28 \%$ \\
\hline PRODUCT 46 & 0.27 & 0.05 & 0.19 & 0.22 & 0.04 & $\mathbf{0 . 0 3}$ & $\mathbf{0 . 0 2}$ & 0.04 & 0.08 & \begin{tabular}{|l|}
0.04 \\
\end{tabular} & $9.91 \%$ \\
\hline PRODUCT 47 & 0.21 & 0.07 & 0.07 & \begin{tabular}{|l|}
$\mathbf{0 . 0 7}$ \\
\end{tabular} & 0.20 & 0.01 & $\mathbf{0 . 0 0}$ & 0.07 & 0.08 & \begin{tabular}{|l|}
$\mathbf{0 . 0 7}$ \\
\end{tabular} & $8.61 \%$ \\
\hline PRODUCT 48 & 0.26 & 0.10 & 0.15 & 0.12 & 0.06 & 0.08 & 0.04 & 0.02 & 0.01 & 0.06 & $8.91 \%$ \\
\hline PRODUCT 49 & 0.08 & 0.04 & 0.14 & \begin{tabular}{|l|}
0.03 \\
\end{tabular} & \begin{tabular}{|l|}
0.23 \\
\end{tabular} & 0.05 & 0.05 & 0.08 & 0.03 & 0.16 & $8.96 \%$ \\
\hline PRODUCT 50 & 0.05 & 0.02 & 0.03 & \begin{tabular}{|l|}
0.01 \\
\end{tabular} & 0.22 & 0.03 & 0.39 & 0.02 & 0.05 & \begin{tabular}{|l|}
0.07 \\
\end{tabular} & $8.93 \%$ \\
\hline PRODUCT 51 & 0.07 & 0.03 & 0.02 & \begin{tabular}{|l|}
0.05 \\
\end{tabular} & \begin{tabular}{|l|}
0.01 \\
\end{tabular} & 0.09 & 0.20 & 0.13 & \begin{tabular}{|l|}
0.09 \\
\end{tabular} & \begin{tabular}{|l|}
0.12 \\
\end{tabular} & $8.12 \%$ \\
\hline PRODUCT 52 & 0.04 & 0.32 & 0.12 & \begin{tabular}{|l|}
0.10 \\
\end{tabular} & \begin{tabular}{|l|l|}
0.10 \\
\end{tabular} & \begin{tabular}{|l|l|}
0.06 \\
\end{tabular} & $\mathbf{0 . 0 3}$ & 0.03 & \begin{tabular}{ll|}
0.00 \\
\end{tabular} & $\mathbf{0 . 0 7}$ & $8.75 \%$ \\
\hline PRODUCT 53 & 0.02 & 0.09 & 0.00 & \begin{tabular}{|l|}
0.18 \\
\end{tabular} & \begin{tabular}{|l|}
0.08 \\
\end{tabular} & \begin{tabular}{|l|}
0.12 \\
\end{tabular} & 0.13 & 0.06 & 0.15 & \begin{tabular}{|l|}
0.08 \\
\end{tabular} & $9.20 \%$ \\
\hline PRODUCT 54 & 0.10 & 0.12 & 0.19 & \begin{tabular}{|l|}
0.01 \\
\end{tabular} & 0.13 & \begin{tabular}{|l|l|}
0.04 \\
\end{tabular} & 0.13 & 0.03 & 0.24 & \begin{tabular}{|l|}
0.00 \\
\end{tabular} & $9.92 \%$ \\
\hline PRODUCT 55 & 0.10 & 0.03 & 0.08 & 0.00 & 0.08 & 0.02 & 0.01 & 0.14 & 0.25 & 0.08 & $7.94 \%$ \\
\hline PRODUCT 56 & 0.04 & 0.02 & 0.15 & 0.35 & \begin{tabular}{|l|l|}
0.09 \\
\end{tabular} & \begin{tabular}{|l|l|}
0.13 \\
\end{tabular} & 0.01 & \begin{tabular}{|l|}
0.07 \\
\end{tabular} & 0.14 & \begin{tabular}{|l|}
0.02 \\
\end{tabular} & $10.17 \%$ \\
\hline
\end{tabular}




\subsection{Inventory management}

For the analysis of the classical EOQ indicated in equation 1 . The following relevant costs are considered. The cost of keeping each unit in inventory $(\mathrm{Ch})$ is $5 \%$ of the selling price (price), the cost to order (Co) is $\$ 3.75$ for each unit requested and the level of service that has been considered for products in classification A of $95 \%$ according to equation 6 due to the importance, they represent for the company.

$$
z_{\text {score }}(0.95)=1.644854
$$

Likewise, the total cost incurred in such products will be considered (Table 4), which will allow the comparison of EOQ about the forecasts generated which are considering the seasonality of the products on an annual basis. Comparing the costs incurred when using the EOQ model (Equation 8) and the seasonal forecast (Equation 9), the inventory value is $14 \%$ lower, this demonstrates the effectiveness of an adequate estimate for increasing cash flow. The assumption of using seasonal forecasts considers a weekly order that covers the demand adjusted to this period based on the projected monthly demand. To absorb any variations that may exist is also considered a safety stock (Equation 7), taking into account service level (Equation 6) and delivery time.

$$
\begin{aligned}
\mathrm{SS}= & (\sigma)(z) \sqrt{L} \\
T C_{E O Q}=\left(\frac{D}{Q}\right)(C o)+ & \left(\frac{Q}{2}\right)(C h)+\left(\frac{Q}{2}\right)(\text { Price }) \\
T C_{F C S T}= & \left(\frac{D_{f c s t}}{2 * 4_{w k}}\right)(\text { Co })+\left(\frac{D_{f c s t}}{2 * 4 w k}\right)(C h)+ \\
& \left(\frac{D_{f c s t}}{2 * 4_{w k}}\right)(\text { Price })
\end{aligned}
$$

Where:

$S S=$ Safety stock,

$\sigma=$ Standard deviation within the sampled values,

$L=$ Lead time of each product,

$T C_{E O Q}=$ Total costs related to a classical economic order quantity considering inventory value,

$D=$ Forecasted demand for the whole planning horizon,

$Q=$ Economic order quantity,

$C o=$ Ordering cost for each product,

$C h=$ Holding cost within planning horizon,

Price $=$ Selling price for each product,

$T C_{F C S T}=$ Total cost associated with the proposed forecasting model,

$D_{f c s t}=$ Period specific forecasted demand .

\section{$5 \quad$ Result and discussion}

For the case study, it was found that traditional time series forecasting methods are not optimal due to the so variable nature of the demand in the products. Being that the closest model is the centred moving average, with an error greater than $25 \%$, so its application is not viable because its accuracy is only reasonable (Figure 2), directly affecting the level of service sought by the company. Although 20\% MAPE is considered a good result [34], for the company's indicators, this is an inadequate value that would not satisfy the needs of its customers, as well as the value of inventory in each period. On the other hand, the implementation of forecast techniques that consider the seasonality of demand offers a highly accurate forecast. Calculating demand forecast with error minimum will help meet the objectives of the company without sacrificing service level.

It is observed that despite increasing the number of orders and changing the economic lot size, the savings in terms of inventory value continue to exceed the cost of ordering material. It combined with the lack of minimum order size for most of the products and having only one supplier, favours the implementation of this improvement. Importance of apply forecast methods, ABC classification and EOQ model is demonstrated that the total costs associated can be reduced. It is crucial to complement classical models with case-specific variables, such as in this scenario, the selling price had a key role in replenishment decisions. Before this study, the cost of materials was overlooked by the company, resulting in non-healthy stock levels for products with low demand. Beginning with the $\mathrm{ABC}$ classification, something new for the company, stakeholders will have the capability to focus their efforts to make sure the top products are always available for their customers and, in contrast, they will be able to carefully follow up those materials that do not have an added value and decide whether it necessary to keep them in inventory. 
FORECASTING DEMAND IMPROVEMENT FOR REPLENISHMENT IN A RETAIL PAINTING COMPANY

Hugo Briseño-Oliveros; Luis Antonio Guzmán-García; Patricia Cano-Olivos; Diana Sánchez-Partida

\begin{tabular}{|c|c|c|c|c|c|c|c|c|c|c|}
\hline PRODUCT & $\begin{array}{c}\text { Annual } \\
\text { forecast } \\
\text { (pieces) }\end{array}$ & $\begin{array}{c}\text { Monthly } \\
\sigma \text { (pieces) }\end{array}$ & $\begin{array}{l}\text { Monthly } \\
\text { demand } \\
\text { (pieces) }\end{array}$ & $\begin{array}{l}\text { Unit price } \\
\text { (MXP) }\end{array}$ & $\begin{array}{c}\text { SS } \\
\text { (pieces) }\end{array}$ & $\begin{array}{c}\mathbf{Q}^{*} \\
\text { (pieces) }\end{array}$ & $\begin{array}{l}\text { \# of orders } \\
\text { with EOQ }\end{array}$ & $\begin{array}{c}\text { TC EOQ } \\
\text { (MXP) }\end{array}$ & $\begin{array}{c}\text { Monthly } \\
\text { forecast } \\
\text { (pieces) }\end{array}$ & $\begin{array}{c}\text { TC } \\
\text { Forecast } \\
\text { (MXP) }\end{array}$ \\
\hline PRODUCT 1 & 280 & 10.74 & 23 & $1,533.00$ & 6 & 5 & 56 & $4,253.32$ & 29 & $5,876.18$ \\
\hline PRODUCT 2 & 268 & 8.97 & 22 & $1,533.00$ & 6 & 5 & 54 & $4,244.32$ & 15 & $3,039.40$ \\
\hline PRODUCT 3 & 43 & 2.19 & 4 & $1,533.00$ & 2 & 2 & 22 & $1,697.95$ & 4 & 810.51 \\
\hline PRODUCT 4 & 52 & 3.89 & 4 & $1,533.00$ & 3 & 2 & 26 & $1,714.84$ & 9 & $1,823.64$ \\
\hline PRODUCT 5 & 89 & 5.89 & 7 & $1,533.00$ & 4 & 3 & 30 & $2,537.23$ & 11 & $2,228.90$ \\
\hline PRODUCT 6 & 151 & 7.53 & 13 & $2,173.00$ & 5 & 3 & 50 & $3,627.56$ & 25 & $7,175.60$ \\
\hline PRODUCT 7 & 60 & 3.02 & 5 & $1,993.00$ & 2 & 2 & 30 & $2,215.14$ & 2 & 526.57 \\
\hline PRODUCT 8 & 135 & 5.99 & 11 & $1,945.50$ & 4 & 3 & 45 & $3,247.54$ & 19 & $4,883.45$ \\
\hline PRODUCT 9 & 57 & 1.85 & 5 & $1,473.00$ & 2 & 2 & 29 & $1,660.92$ & 4 & 778.86 \\
\hline PRODUCT 10 & 298 & 5.05 & 25 & $1,071.00$ & 6 & 6 & 50 & $3,576.00$ & 28 & $3,967.67$ \\
\hline PRODUCT 11 & 156 & 5.23 & 13 & $2,173.00$ & 6 & 3 & 52 & $3,633.82$ & 14 & $4,018.34$ \\
\hline PRODUCT 12 & 54 & 3.61 & 5 & $2,173.00$ & 3 & 2 & 27 & $2,393.77$ & 4 & $1,148.10$ \\
\hline PRODUCT 13 & 41 & 1.75 & 3 & $2,173.00$ & 1 & 2 & 21 & $2,369.38$ & 6 & $1,722.14$ \\
\hline PRODUCT 14 & 129 & 6.61 & 11 & $2,173.00$ & 4 & 3 & 43 & $3,600.04$ & 28 & $8,036.67$ \\
\hline PRODUCT 15 & 126 & 4.35 & 11 & $2,385.00$ & 3 & 3 & 42 & $3,931.76$ & 13 & $4,094.75$ \\
\hline PRODUCT 16 & 100 & 4.27 & 8 & $2,385.00$ & 3 & 2 & 50 & $2,703.74$ & 11 & $3,464.79$ \\
\hline PRODUCT 17 & 34 & 2.22 & 3 & $2,385.00$ & 3 & 1 & 34 & $1,385.65$ & 4 & $1,259.92$ \\
\hline PRODUCT 18 & 50 & 1.79 & 4 & $2,385.00$ & 1 & 2 & 25 & $2,609.92$ & 3 & 944.94 \\
\hline PRODUCT 19 & 62 & 2.54 & 5 & $2,385.00$ & 2 & 2 & 31 & $2,632.44$ & 9 & $2,834.83$ \\
\hline PRODUCT 20 & 37 & 1.80 & 3 & $1,993.00$ & 2 & 2 & 19 & $2,171.98$ & 2 & 526.57 \\
\hline PRODUCT 21 & 62 & 2.25 & 5 & $1,993.00$ & 2 & 2 & 31 & $2,218.89$ & 5 & $1,316.44$ \\
\hline PRODUCT 22 & 39 & 1.19 & 3 & $2,185.00$ & 1 & 2 & 20 & $2,378.28$ & 5 & $1,443.03$ \\
\hline PRODUCT 23 & 28 & 3.10 & 2 & $2,283.00$ & 2 & 1 & 28 & $1,309.33$ & 1 & 301.53 \\
\hline PRODUCT 24 & 392 & 19.14 & 33 & 352.50 & 11 & 12 & 33 & $2,353.85$ & 45 & $2,112.91$ \\
\hline PRODUCT 25 & 318 & 13.08 & 27 & 352.50 & 8 & 11 & 29 & $2,153.81$ & 33 & $1,549.47$ \\
\hline PRODUCT 26 & 209 & 13.69 & 17 & 352.50 & 8 & 9 & 23 & $1,760.59$ & 21 & 986.02 \\
\hline PRODUCT 27 & 404 & 13.50 & 34 & 497.50 & 8 & 11 & 37 & $3,024.49$ & 41 & $2,709.07$ \\
\hline PRODUCT 28 & 105 & 5.74 & 9 & 617.00 & 4 & 5 & 21 & $1,706.10$ & 16 & $1,309.33$ \\
\hline PRODUCT 29 & 363 & 8.99 & 30 & 243.50 & 6 & 14 & 26 & $1,895.50$ & 33 & $1,075.13$ \\
\hline PRODUCT 30 & 477 & 7.72 & 40 & 148.50 & 5 & 21 & 23 & $1,730.20$ & 43 & 862.23 \\
\hline PRODUCT 31 & 370 & 13.46 & 31 & 497.50 & 8 & 10 & 37 & $2,763.09$ & 49 & $3,237.66$ \\
\hline PRODUCT 32 & 212 & 5.40 & 18 & 497.50 & 4 & 8 & 27 & $2,198.84$ & 30 & $1,982.24$ \\
\hline PRODUCT 33 & 158 & 6.26 & 13 & 497.50 & 4 & 7 & 23 & $1,921.67$ & 23 & $1,519.72$ \\
\hline PRODUCT 34 & 185 & 10.71 & 15 & 497.50 & 6 & 7 & 26 & $1,936.15$ & 21 & $1,387.57$ \\
\hline PRODUCT 35 & 368 & 17.33 & 31 & 497.50 & 10 & 10 & 37 & $2,762.34$ & 65 & $4,294.86$ \\
\hline PRODUCT 36 & 170 & 6.24 & 14 & 542.50 & 4 & 7 & 24 & $2,094.26$ & 26 & $1,872.23$ \\
\hline PRODUCT 37 & 216 & 8.06 & 18 & 542.50 & 5 & 7 & 31 & $2,118.92$ & 29 & $2,088.26$ \\
\hline PRODUCT 38 & 134 & 4.88 & 11 & 542.50 & 3 & 6 & 22 & $1,800.77$ & 19 & $1,368.17$ \\
\hline PRODUCT 39 & 113 & 6.30 & 9 & 542.50 & 4 & 5 & 23 & $1,515.61$ & 20 & $1,440.18$ \\
\hline PRODUCT 40 & 266 & 14.34 & 22 & 542.50 & 9 & 8 & 33 & $2,414.06$ & 23 & $1,656.21$ \\
\hline PRODUCT 41 & 161 & 8.23 & 13 & 454.00 & 5 & 7 & 23 & $1,762.66$ & 12 & 724.06 \\
\hline PRODUCT 42 & 1810 & 82.80 & 151 & 31.50 & 47 & 89 & 20 & $1,555.12$ & 104 & 480.80 \\
\hline PRODUCT 43 & 3041 & 41.49 & 253 & 35.50 & 24 & 108 & 28 & $2,128.04$ & 195 & $1,004.35$ \\
\hline PRODUCT 44 & 192 & 12.11 & 16 & 320.00 & 7 & 9 & 21 & $1,599.21$ & 11 & 469.35 \\
\hline PRODUCT 45 & 254 & 9.31 & 21 & 320.00 & 6 & 10 & 25 & $1,783.27$ & 22 & 938.69 \\
\hline PRODUCT 46 & 172 & 6.51 & 14 & 320.00 & 4 & 9 & 19 & $1,590.87$ & 14 & 597.35 \\
\hline PRODUCT 47 & 693 & 23.75 & 58 & 138.50 & 14 & 26 & 27 & $1,999.50$ & 77 & $1,442.46$ \\
\hline PRODUCT 48 & 410 & 13.71 & 34 & 151.00 & 8 & 19 & 22 & $1,594.33$ & 45 & 917.17 \\
\hline PRODUCT 49 & 340 & 9.90 & 28 & $2,404.99$ & 12 & 4 & 85 & $5,393.37$ & 7 & $2,223.32$ \\
\hline PRODUCT 50 & 1524 & 51.51 & 127 & 520.00 & 29 & 20 & 76 & $5,771.80$ & 99 & $6,835.15$ \\
\hline PRODUCT 51 & 2446 & 68.47 & 204 & 51.00 & 39 & 81 & 30 & $2,292.36$ & 180 & $1,295.02$ \\
\hline PRODUCT 52 & 1607 & 88.93 & 134 & 58.00 & 50 & 62 & 26 & $1,994.10$ & 115 & 933.53 \\
\hline PRODUCT 53 & 2698 & 38.08 & 225 & 40.00 & 22 & 96 & 28 & $2,131.01$ & 201 & $1,154.53$ \\
\hline PRODUCT 54 & 178 & 7.12 & 15 & 398.00 & 4 & 8 & 22 & $1,763.01$ & 19 & $1,006.12$ \\
\hline PRODUCT 55 & 5261 & 126.84 & 438 & 133.00 & 142 & 73 & 72 & $5,391.80$ & 351 & $6,320.78$ \\
\hline & 356 & & 30 & & 20 & 10 & & $2,818.49$ & 10 & \\
\hline \multicolumn{11}{|c|}{\begin{tabular}{|c|}
$2,818.49$ \\
$\mathbf{1 3 9 , 8 3 3 . 0 3}$ \\
\end{tabular}} \\
\hline
\end{tabular}




\section{Conclusions}

The time series methods are applicable for products where their demand is stable, with small variations or tendencies to high or low. Nevertheless, for those products in which demand can be variable as in the case of a retail company. It is necessary to analyse the historical sales for choosing an adequate technique that achieve a MAPE less than $10 \%$, so it is a highly reliable forecast and complementing it with the safety stock. It will allow the company to comply with its service policy of $95 \%$, without the need to have an excess of inventory or risks of lost sales. EOQ model does not consider lower inventory costs, demand fluctuations and special-order policies similar. This model involves costs across the entire planning horizon without analysing specific periods within it, which can reduce the cash flow of the company in specific periods, by not considering those low demand in specific periods and risking having shortages in those periods where demand increases.

Therefore, an accurate forecast can reduce inventory costs in each of the periods, satisfying customer demand, by at least $14 \%$ against the classic EOQ methodology. EOQ model should apply to all products for reducing the investment in slow-moving stock and improving the inventory for those highly demanded products which can generate flexibility to embrace market complexity and meet customer expectations in terms of quicker response to spot projects. It is also expected to strengthen the company's qualification to create a partnership between professional contractors to make them choose this company as the first option in their projects due to its high service level. As a future study, it is intended to help the company to develop a strategy to reduce non-rotating inventory knowing more accurately what and when they will sell specific products. This inventory management proposal might be complemented with a marketing campaign to enhance profit results and ultimately improve cash flow.

Another important future study should be consolidated product receptions in one single receiving location to distribute to all the company branches. Instead of having individual inventories, there might be a central location to replenish the stores in a frequent basis, considering the optimisation of the distribution costs associated to this further study, which would be a new variable added to the board. Seasonal demand model must be considered to find specific products that might not fit the proposed methodology since some of them have to be ordered in minimum quantities that might exceed the forecasted demand. For these exceptions, a different inventory management technique should be studied in future research.

\section{Acknowledgement}

This article was supported by the Ph.D. Patricia Cano Olivos as part of the Logistics and Supply Chain Management Master Program.

\section{References}

[1] RAMPL, L.V., EBERHARDT, T., SCHÜTTE, R. KENNING, P.: Consumer trust in food retailers: conceptual framework and empirical evidence, International Journal of Retail and Distribution Management, Vol. 40, No. 4, pp. 254-272, 2012. doi:10.1108/09590551211211765

[2] BINZ, C., HAIR, J.F., PIEPER, T.M., BALDAUF, A.: Exploring the effect of distinct family firm reputation on consumers' preferences, Journal of Family Business Strategy, Vol. 4 No. 1, pp. 3-11, 2013. doi:10.1016/j.jfbs.2012.12.004

[3] ORTH, U.R., GREEN, M.T.: Consumer loyalty to family versus non-family business: the roles of store image, trust and satisfaction, Journal of Retailing and Consumer Services, Vol. 16 No. 4, pp. 248-259, 2009. doi:10.1016/j.jretconser.2008.12.002

[4] EDDLESTON, K.A., CHRISMAN, J.J., STEIER, L.P., CHUA, J.H.: Governance and trust in family firms: an introduction, Entrepreneurship Theory and Practice, Vol. 34 No. 6, pp. 1043-1056, 2010. doi:10.1111/j.1540-6520.2010.00412.x

[5] DEBICKI, B.J., MATHERNE, C.F., KELLERMANNS, F.W., CHRISMAN, J.J.: Family business research in the new millennium - An overview of the who, the where, the what, and the why, Family Business Review, Vol. 22 No. 2, pp. 151-166, 2009. doi:10.1177/0894486509333598

[6] CRUZ, C.C., GÓMEZ-MEJIA, L.R., BECERRA, M.: Perceptions of benevolence and the design of agency contracts: CEO-TMT relationships in family firms, Academy of Management Journal, Vol. 53, No. 1, pp. 69-89, 2010. doi:10.5465/amj.2010.48036975

[7] CARRIGAN, M., BUCKLEY, J.: What's so special about family business?An exploratory study of UK and Irish consumer experiences of family businesses, International Journal of Consumer Studies, Vol. 32, No. 6, pp. 656-666, 2008. doi:10.1111/j.14706431.2008.00696.x

[8] BECK, S., KENNING, P.: The influence of retailers' family firm image on new product acceptance. International Journal of Retail \& Distribution Management, Vol. 43, No. 12, pp. 1126-1143, 2015. doi:10.1108/ijrdm-06-2014-0079

[9] NAGASHIMA, M., WEHRLE, F. T., KERBACHE, L., LASSAGNE, M.: Impacts of adaptive collaboration on demand forecasting accuracy of different product categories throughout the product life cycle, Supply Chain Management: An International Journal, Vol. 20, No. 4, pp. 415-433, 2015. doi:10.1108/scm-03-20140088

[10] LERE, J. C.: Activity-based costing: a powerful tool for pricing. Journal of Business \& Industrial Marketing, Vol. 15, No. 1, pp. 23-33, 2000. doi:10.1108/08858620010311539

[11] SARMAH, S. P., MOHARANA, U. C.: Multi-criteria classification of spare parts inventories $-\mathrm{a}$ web based 
approach. Journal of Quality in Maintenance Engineering, Vol. 21, No. 4, pp. 456-477, 2015. doi:10.1108/jqme-04-2012-0017

[12] HOFMANN, E., BOSSHARD, J.: Supply chain management and activity-based costing, International Journal of Physical Distribution \& Logistics Management, Vol. 47, No. 8, pp. 712-735, 2017. doi:10.1108/ijpdlm-04-2017-0158

[13] FORRESTER, J. W.: Industrial dynamics: A major breakthrough for decision makers, Harvard Business Review, Vol. 36, No. 4, pp. 37-66, 1958. doi.10.1225/58404

[14] LEE, H. L., PADMANABHAN, V., WHANG, S.: The bullwhip effect in supply chains, Sloan Management Review, Vol. 38, No. 3, pp. 93-102, 1977.

[15] CHRISTOPHER, M., LEE, H.: Mitigating supply chain risk through improved confidence, International Journal of Physical Distribution and Logistics Management, Vol. 34, No. 5, pp. 388-396, 2004. doi.10.1108/09600030410545436

[16] GUNASEKARAN, A., PATEL, C., MCGAUGHEY, R. E.: A framework for supply chain performance measurement, International Journal of Production Economics, Vol. 87, No. 3, pp. 333-347, 2004. doi:10.1016/j.ijpe.2003.08.003

[17] TEMPLAR, S., HOFMANN, E. AND FINDLAY, C.: Financing the End-to-End Supply Chain, London, Kogan Page, 2016.

[18] HOFFJAN, A., LÜHRS, S., KOLBURG, A.: Cost Transparency in Supply Chains: Demystification of the Cooperation Tenet, Schmalenbach Business Review, Vol. 63, No. 3, pp. 230-251, 2011. doi: $10.1007 / \mathrm{bf03396819}$

[19] SILVER, E.: Inventory Management: An Overview, Canadian Publications, Practical Applications, and Suggestions for Future Research, INFOR Information Systems and Operational Research, Vol. 46, No.1, pp. 1-32, 2008. doi:10.3138/infor.46.1.15

[20] IZAR, J., YNZUNZA, C., ZERMEÑO, E.: Reorder point calculation when lead time and demand are correlated (Original in Spanish), Contaduría y Adminisitración, Vol. 60, No. 4, pp. 864-873, 2015. doi:10.1016/j.cya.2015.07.003

[21] TAHA, H.: Investigación de Operaciones, $7^{\mathrm{a}}$ edition, México, Pearson Prentice Hall, 2004.

[22] CHIKÁN, A.: The new role of inventories in business: Real world changes and research consequences, International Journal of Production Economics, Vol.
108, No. 1-2, pp. 54-62, 2007. doi:10.1016/j.ijpe.2006.12.002

[23] WALKER, W.: Supply Chain Construction: The Basics for Networking the Flow of Material, Information, and Cash, New York, CRC Press, 2016.

[24] HOLWEG, M., PIL, F.: The Second Century: Reconnecting Customer and Value Chain through Build to Order, Massachusetts, The MIT Press, 2004.

[25] DWIVEDI, A., BUTCHER, T.: Supply Chain Management and Knowledge Management, England, Macmillan, 2009.

[26] EAGLE, S.: Demand-Driven Supply Chain Management-Transformational Performance Improvement, New York, Kogan Page, 2017.

[27] RUSANESCU, M.: ABC analysis, model for classifying inventory, Magazine of Hydraulics, Pneumatics, Tribology, Ecology, Sensorics, Mechatronics, Vol. 2014, No. 2, pp. 17-20, 2014.

[28] ULTSCH, A.: Proof of Pareto's 80/20 Law and Precise Limits for ABC-Analysis, Technical Report 2002/c DataBionics Reseach Group, Lahn, Germany, pp. 1-11, 2002.

[29] HESHAM, K., GHAITHAN, A.: EOQ and EPQ Production-Inventory Models with Variable Holding, Arabian Journal for Science and Engineering, Vol. 44, No. 3, pp. 1-19, 2018. doi:10.1007/s13369-0183593-4

[30] PARKHI, S., D. J., KUMAR, A.: A Study on Transport Cost Optimization in Retail Distribution, Journal of Supply Chain Management System, Vol. 3, No. 4, pp. 31-38, 2014.

[31] TÀPIES, J.: Family business: An interdisciplinary approach, Universia Business Review, Vol. 32, No. 32, pp. 12-25, 2011. (Original in Spanish)

[32] VELEZ-PAREJA, I.: A Simple Approach to Forecasting Methods, SSRN, Vol. 2003, No. October, pp. 5-7, 2003. doi:10.2139/ssrn.986879 (Original in Spanish)

[33] CARLBERG, C.: Excel Sales Forecasting For Dummies, $2^{\text {nd }}$ Edition, New Jersey, John Wiley \& Sons, Inc., 2016.

[34] LEWIS, C.: Industrial and business forecasting methods: a practical guide to exponential smoothing and curve fitting, London, Boston: Butterworth Scientific, 1982.

\section{Review process}

Single-blind peer review process. 